Dunaetz, D. R. (2014). Recovered memories and accusations of sexual abuse: A review of scientific research relevant to missionary contexts. In D. Baker and R. Priest (Eds.), The missionary family: Witness, concerns, care (pp. 163-181). Pasadena, CA: William Carey Library.

\title{
Recovered Memories and Accusations of Sexual Abuse: A Review of Scientific Research Relevant to Missionary Contexts
}

\author{
David Dunaetz \\ Azusa Pacific University
}

\begin{abstract}
Childhood sexual abuse of missionary children is a tragedy that mission organizations are seeking to prevent. A second tragedy concerns missionaries falsely accused of sexual abuse. Psychotherapy that generated false memories of sexual abuse was common in the 1980s and 1990s and still continues to some degree today in Christian circles. This chapter reviews scientific evidence that such false memories exist and provides guidelines that Christian organizations may use to help sort true memories of childhood sexual abuse from false memories of childhood sexual abuse.
\end{abstract}

The consequences of childhood sexual abuse are devastating. Victims experience higher levels of depression, posttraumatic stress disorder (PTSD), anxiety disorders, alcoholism, antisocial behavior, social phobia, and attempted suicide (Widom 1999, Levitan et al. 2003, Dinwiddie et al. 2000). Although the vast majority of cases of childhood sexual abuse occur within the context of the child's family (Health and Human Services 2009), cases of abuse by clergy and other full-time Christian workers is a tragic problem (Nussbaum and Sidebotham 2011, Terry et al. 2011).

Between 1950 and 2000, approximately $4 \%$ of Catholic priests were accused of sexual abuse of a minor (Terry et al. 2011); one estimate of pedophilia among protestant workers is $2-3 \%$ (Rediger 1990), but the prevalence of sexual abuse in protestant ministries is difficult to estimate because of the lack of a central organization. Nevertheless, insurance companies (which have access to the most reliable records) charge protestant and Catholic organizations approximately equal rates for sexual misconduct coverage, although organizations with large children's ministries are charged higher rates (Nussbaum and Sidebotham 2011).

There is strong evidence that the prevalence of childhood sexual abuse in religious contexts has declined sharply since the early 1990s when the dangers of such abuse became more widely known and policies were instituted to limit its likelihood of occurring (Terry et al. 2011). In the Catholic church, childhood sexual abuse by clergy was especially prevalent from

Dunaetz, D. R. (2014). Recovered memories and accusations of sexual abuse: A review of scientific research relevant to missionary contexts. In D. Baker and R. Priest (Eds.), The missionary family: Witness, concerns, care (pp. 163-181). Pasadena, CA: William Ca rey Library. 
1955 to 1995 , peaking during the late 1970 s and early 1980s with rates approximately 50 times higher than the present (Terry et al. 2011). It is quite possible that a similar trend occurred in Protestant ministries as sexual mores evolved in Western cultures to become more sexually permissive from the 1950 s to the 1970 s and awareness of the importance of protecting minors from sexual abuse increased in the 1980s and 1990s. An internet search of "missionary abuse" quickly provides documented cases of abuse in evangelical missions that also occurred during this period (e.g., the confession at http://www.youtube.com/watch?v=kT9j8WNAw $1 \mathrm{M})$.

In addition to the catastrophic aftereffects of childhood sexual abuse experienced by the victims of the abuse, there may be other innocent parties who also suffer unfair, negative consequences. It is possible that not all accusations of sexual abuse may be true. If such false accusations are made, the consequences of these accusations may be quite real, resulting in criminal prosecution, shattered relationships, and terminated careers (Loftus and Ketcham 1994, Pendergrast 1996), even among evangelical missionaries (Priest and Cordill 2012). At the heart of the controversy surrounding false accusations lies the concept of recovered memories, memories of traumatic abuse that had supposedly been repressed (subconsciously blocked) but have once again become conscious. At the end of the 19th century Freud (1896/1962) was the first to propose that traumatized individuals may repress memories in order to protect themselves. During the 1980s and early 1990s, the concept was popularized by the press, spurred on by fascination with the McMartin Preschool case (Young 1997). The moral panic that ensued, interacting with the popularity of the New Age movement, led many psychotherapists to develop therapies that involved suggesting to clients that they had previously been abused by those closest to them (Singer and Nievod 2003, Loftus and Rosenwald 1993). At the same time, various Christian groups focused on recovering repressed memories. At least one book from that period that advocates recovering memories of supposed repressed abuse (and filing civil suits against the alleged perpetuators), Courage to Heal (Bass and Davis 1988), is still popular in Christian circles and is available through Christian book distributors (e.g., christianbooks.com and cokesbury.com). For a review of the extent to which such ideas are present in Christian literature, see the work by Priest and Cordill (2012).

However, since the mid-1990s, there has been a movement away from belief in repressed and recovered memories in academic circles (Loftus and Ketcham 1994, Maran 2010, Pendergrast 1996). Many recovered memories are now considered false memories. Although there is presently a general consensus in the scientific community concerning the dangers of false memories, many counselors and therapists, including many who are evangelical Christians, are not aware of the advances made by the cognitive sciences and the dangers associated with false memories (Lacy and Stark 2013, Patihis et al. in press). This is an important issue for mission organizations because accusations of child abuse by their members must be dealt with appropriately. Most, if not all, mission organizations want to act quickly and decisively to stop any abuse that has occurred, remove child abusers from their organizations, and provide all the support possible to victims of the abuse. However, acting upon false accusations of abuse may have extremely negative consequences on those accused of abuse, potentially destroying both their careers and their families.

In order to help mission organizations to respond properly to accusations of abuse, three questions will be addressed in these pages:

1. Is there scientific evidence that recovered memories truly exist? If so, under what conditions?

2. Is there scientific evidence that false memories occur? If so, under what conditions?

3. In missionary contexts, what indicators do we have that a memory is more likely to be false?

With answers to these questions, leaders of mission organizations should be able to act more wisely and justly in order to protect the innocent, help the abused, and discipline the guilty. Developing this ability to respond justly is not only beneficial for those directly involved, but creates an atmosphere of trust in the organization that enables all its members to function more effectively for the glory of God (Dunaetz 2010).

\section{Scientific Evidence Concerning Recovered Memories}

Although the repression of traumatic memories has long been hypothesized, and the concept has firmly taken root in Western culture, it was only in the past 30 years, as accusations of 
childhood sexual abuse multiplied, that the question of whether recovered repressed memories actually exist (and if so, under what conditions) has been seriously researched by cognitive psychologists. To demonstrate that recovered memories of repressed trauma exist, three criteria (Pope and Hudson 1995) must be met:

1. It must be demonstrated that abuse took place.

2. It must be demonstrated that the memory of the abuse was forgotten and inaccessible for a period of time.

3. The abuse must later be remembered accurately.

It would be unethical to conduct experiments to test whether memories of trauma could be repressed and recovered. Researchers must depend on cases studies, retrospective studies (studies involving participants who already claim to have recovered memories), prospective studies (studies of victims of confirmed abuse who are interviewed to discover if they can remember the abuse), or corroboration studies (where evidence of abuse is examined for people who claim to recall forgotten abuse).

Evidence from Case Studies. Much of the popular literature on repressed memories is based on case studies by individual therapists. Due to confidentiality, it is difficult or impossible to verify if these individuals were actually victims of abuse (Loftus and Davis 2006). The subjects of these studies certainly believe that they were abused, but actual evidence that they were abused usually does not exist, limiting the usefulness of case studies. In a well-known Jane Doe case (Corwin and Olafson 1997), Loftus and Guyer (2002) demonstrated, using public records to track down the individuals involved, that it is highly unlikely that the supposed abuse by the mother actually occurred; the memories of abuse were most likely implanted by the father and step-mother during a custody battle. In most cases, the only verification that occurs is the supposed victim's word that abuse occurred.

Therapists who report recovered memories may be highly motivated to believe that these memories are of authentic events. During the 1980s and 1990s recovering repressed memories was a major generator of income for certain therapists. The financial incentives that come from being able to produce memories with such emotional impact may prevent therapists from being unbiased in their interpretation of common symptoms such as depression and anxiety, which occur among both the abused and the non-abused. Practices involving direct suggestion, guided imagery, hypnosis, age regression, or dream analysis have been common techniques (in spite of the controversy that has surrounded each) used by therapists to recover supposedly repressed memories. There is perhaps less motivation now for mental health professionals to recover repressed memories in clients. Both the American Medical Association (1994) and the American Psychiatric Association (American Psychiatric Association 1994) have made statements warning of the dangers of these techniques. In addition, therapists have been sued for implanting false memories and have had their licenses revoked (Robbins 2002). Nevertheless, both licensed and unlicensed therapists and counselors, especially those who were trained before the turn of the century or who were trained at professional schools (e.g. many Christian schools, in contrast to research universities), may still use memory recovery techniques.

Evidence from Retrospective Studies. Like case studies, most retrospective studies (studies of individuals who have already recalled the supposed abuse) have not provided evidence that the abuse actually occurred. If evidence is provided, its verification is typically ambiguous (Loftus and Davis 2006), such as an out-of-court settlement without an admission of guilt or joining an online incest survivors group without having memories of being abused. However, in some cases, the abuse has been verified (McNally and Geraerts 2009).

In most cases of childhood sexual abuse, the trauma is not forgotten. Events that are traumatic are strongly imprinted on the mind and are difficult to forget, often leading to posttraumatic stress disorder (Yehuda 2002). Forgetting traumatic events is especially difficult when there are physical reminders of the abuse, such as interactions with the abuser, discussions that mention the abuser, or remaining in (or returning to) the place of abuse. These reminders prevent victims from forgetting their experience. Nevertheless, there are some situations when the abuse is forgotten. This occurs most often when the abuse is not considered traumatic at the time, when the abuse is not interpreted as sexual, or when the abuse occurs when the child is very young (McNally and Geraerts 2009).

It may seem difficult to believe that sexual abuse may not be viewed by the victim as 
traumatic or sexual at the time the abuse occurred. However, sexual abusers often try to make their actions unnoticeable. For example, a three year old may not be able to distinguish between groping and roughhousing. Such abusers would most likely be caught only if a third party adult observed the act. It is quite possible that the three year old will have little or no memory of the event. The fact that child abuse is not always viewed as traumatic can help explain why approximately $50 \%$ of adults who are raped (both male and female) suffer from PTSD but only about $20 \%$ of children who were sexually abused develop PTSD (Yehuda 2002, Kessler et al. 1995). Similarly, even teens may not view the abuse as sexual. A teenage boy might be touched inappropriately by a youth worker, but shrugs it off as an accident. Only later, perhaps years later, when he shares his experience with others and hears that they, too, were touched inappropriately by the same youth worker, will he understand that this was most likely a form of sexual abuse.

In such cases, the abuse is generally not forgotten or repressed. However, the victim might not have had a reason to recall the events or to think of them for a period of several years or more. Such memories remain accessible and, if required, can be recalled. The retrieval may occur spontaneously when some reminder of the events occurs, such as a discussion concerning the abuser or revisiting the place where the abuse occurred. However, these cases cannot be considered repression since the memories have always been accessible, although the victim might interpret the recalled memory as having been repressed (Loftus and Davis 2006, McNally and Geraerts 2009).

Evidence from Prospective Studies. Studies of victims of confirmed abuse who are interviewed to discover if they can remember the abuse are called prospective studies. In one very wellknown study, Williams (1994) examined interviews about unwanted sexual experiences from 129 women with hospital records indicating childhood sexual abuse. Over a third of them did not mention the recorded events, which the author interpreted as evidence of repressed memory. Although this study has often been cited (even in Christian circles, e.g., Tracy 2005) to demonstrate that a large percentage of abused women repress memories, it has been strongly criticized because phenomena other than repression could account for the women not telling the interviewers about the event (Loftus and Davis 2006). Many of the acts of abuse occurred when the child was less than two years old; normal childhood amnesia (Perner and Ruffman 1995), not repression, is a better explanation of why some of these events were not recalled. Also, the study was designed so that the interviewer would specifically not mention to the victim the verified act of abuse; if that act had been mentioned, perhaps the victim would have been able or willing to recall it. It is also quite possible that some of the women, who did not previously know the interviewers, chose not to reveal to a stranger all of their memories of unwanted sexual abuse which might have included the verified abuse.

In an attempt to reproduce the Williams (1994) study, Goodman and colleagues (Goodman et al. 2003) found a much smaller percentage of victims who were unable to recall verified abuse. Those who were younger when the abuse occurred, who received little emotional support from their mothers, and who were less severely abused were less likely to recall the abuse. In such situations, the events were apparently not experienced as highly traumatic at the time they occurred. In addition, people who tended to frequently have dissociative experiences (instances of being unable to integrate real events into one's thoughts, e.g. finding themselves somewhere without knowing how they got there, or not being able to remember important events in their lives such as their wedding) were also less likely to recall the childhood sexual abuse. Often dissociation is likely to be a defense mechanism to protect oneself from painful memories of traumatic events (Goodman et al.2003), and in these cases repression might have truly occurred (but see Holmes et al. 2005 for an alternative view).

Evidence from Corroborative Studies. Another line of evidence, corroborative studies, examines the verification rates of childhood sexual abuse memories that were perceived as being previously forgotten and are now considered remembered. Corroboration may come from the testimony of people abused by the same person (who did not forget the abuse), the testimony of people who either witnessed the abuse or discovered it near the time it occurred, or the confession of the perpetrator. Various studies (McNally and Geraerts 2009, McNally et al. 2006, Geraerts et al. 2007) have found that the corroborative rate of spontaneously recovered memories (e.g., recovered outside of therapy due to some reminder of the incident such as a discussion or 
visiting the place of abuse) is about $40 \%$, approximately the same as for never forgotten memories of abuse. However, memories recovered during therapy have corroboration rates of only $0-3 \%$. These low corroboration rates are not consistent with the hypothesis that accurate memories are often repressed and restored during psychotherapy. However, they are consistent with the hypothesis that interactions with therapists (who may actively seek to recover repressed memories) may generate false memories of abuse (Geraerts et al. 2007). In summary, it does not appear that traumatic sexual abuse is often repressed, later to be recalled in therapy (Goodman, Quas, and Ogle 2010, Loftus and Davis 2006). It is possible that some victims, especially those suffering from dissociation, might experience memory loss of traumatic events, but normal forgetting (due to childhood amnesia or because the events were not perceived as traumatic) is a more likely mechanism by which memories of childhood sexual abuse are lost (Goodman et al. 2003). Therefore, allegedly recovered memories of repressed childhood sexual abuse could, in fact, be false memories, a hypothesis which will now be considered.

\section{Scientific Evidence Concerning False Memories}

Is it possible for people to develop false memories, memories of events which never really happened? We will first consider the experience of people who claim to have recovered memories of abuse in therapy or in support groups. Secondly, we will consider laboratory evidence that false memories can be implanted in unsuspecting individuals.

Impossible False Memories of Trauma. In most cases of recovered memories of childhood sexual abuse, it is impossible to determine if the abuse occurred or not. However, a number of reported recovered memories of abuse and trauma have proven to be false. These include memories of having been gang-raped in a Satanist organization although the person's hymen remained unaltered, memories of having had one's clitoris removed although a medical doctor verified its presence, and memories of witnessing the murder of a person later found to be still alive (Schacter 1996, 2001, McNally 2003, Loftus and Davis 2006). Other memories that cannot be true, but which are sometimes claimed to be recovered, include those of personal experiences that occurred before the age of six months (e.g., Arnold Barr 1994); such memories are impossible due to juvenile amnesia (Perner and Ruffman 1995).

Other traumatic memories which are relatively common, but are most likely false, concern satanic ritual abuse and space alien abductions. Unlike abuse which may or may not occur, there is less uncertainty with these two phenomena. Although many people claim to be victims of satanic ritual abuse or alien abductions, there is little verifiable evidence for their existence. No large networks of violent Satanists have ever been discovered (Loftus and Ketcham 1994, Loftus and Davis 2006) and 95-100\% of memories of satanic ritual abuse are "recovered" during some type of therapy (McNally 2003). Similarly, no strong evidence for space alien abductions exist, but experimental research on people who believe they remember being abducted by aliens indicates that they (as well as people who claim to recall past lives) are more prone to false memories than people who do not claim to have such memories (McNally 2012).

Additional evidence for false memories comes from retractors, people who had, at one time, claimed to recover false memories but later realized that these memories were false. Some retractors have responded by suing their therapists, a trend that has put a strong damper on the recovered memories movement. Studies of retractors (de Rivera 1997, Lief and Fetkewicz 1995, Ost, Costall, and Bull 2001) have found a common pattern: Individuals seek therapy for depression with therapists who use memory recovery techniques (such as suggestive visualization or hypnosis); this leads to "recovered" memories of abuse and a false accusation of abuse; they later realize that these were false memories implanted by the therapist and retract the accusations that they made.

The experiences of people who have memories of impossible events and the retractions from people who once claimed to have recovered repressed memories of abuse all point to the existence of false memories. Strong evidence for false memories is also found in experimental studies which we will now examine.

Laboratory Studies of False Memories. The abundance of anecdotal evidence and case studies concerning false memories has motivated abroad range of laboratory studies that have experimentally examined the possibility of false memories and the conditions under which they are most likely to be produced. Before looking at who is most vulnerable to false memories, we will 
give an overview of three of the most common experimental designs used to understand false memory: the mousetrap experiment (Ceci et al. 1994), the spilled wedding punch experiment (Hyman, Husband, and Billings 1995), and the Bugs Bunny at Disneyland experiment (Braun, Ellis, and Loftus 2002).

In light of the McMartin Preschool panic (Young 1997) where young children recalled being sexually abused by many preschool teachers and workers in satanic rituals involving underground tunnels and local churches, Ceci and colleagues (1994) conducted a study to find out if preschoolers could develop false memories. Over a period of weeks, preschoolers were repeatedly asked to think about if they had ever had their hand stuck in a mousetrap which had to be removed at the emergency room. Approximately $40 \%$ of the three and four year olds reported that the event truly happened, while more than $30 \%$ of the five and sixyear olds reported that it happened; these proportions were relatively stable throughout the experiment. This experiment demonstrated that false memories could easily be created by suggesting that an event might have happened and that the false memories are relatively stable. Asking preschoolers to think about whether they had experienced something was enough for many of them to believe that they had actually experienced it when, in fact, they had not.

Although it might be easy to create false memories in preschoolers, the question remained as to whether false memories could be created in adults. The spilled punch at a wedding series of studies attempts to implant memories in adults through a false narrative that is supposedly from a trustworthy informant (Hyman, Husband, and Billings 1995, Loftus 2003). Typically, a young adult has been told by the researchers that they have contacted his or her parents to get information about an embarrassing event that occurred when he or she was young. The participant is presented with an embarrassing or memorable story (such as accidently spilling punch on the bride's parents at a wedding) and asked to recall it. The average false memory rate in this type of experiment is $31 \%$ (Lindsay et al. 2004). These experiments demonstrate that false memories can easily be created in many adults when false information is presented by a credible source.

The spilled punch at the wedding experiment demonstrates that is easy to create false memories in adults by using deceptive information. However, the question remains if false memories can be created in adults by simple suggestion. Also, the spilled punch at a wedding experiment was criticized because it is possible that many adults may have actually spilled punch on someone at some event when they were small and their memories of such an event were not completely false. To address these issues, the Bugs Bunny at Disneyland experiment was designed (Braun, Ellis, and Loftus 2002). Participants were exposed to an ad which asked them to remember the feelings they had as a child when they shook Bugs Bunny's hand at Disneyland. As Bugs Bunny is a Warner Brother's character, this was an impossible event. Only participants who had never visited a Six Flags park were included in the study because it is possible they might have met Bugs Bunny there. When later asked if they had ever met Bugs Bunny at Disneyland, between 16\% and $36 \%$ of the participants in these types of studies indicated that they could remember meeting him, some indicating that they remember hugging him, touching his ears, or hearing him say "What's up, Doc?" (Loftus 2003). Thus merely suggesting to adults that they try to remember something can create a false memory of the event.

More recently, quite sophisticated false memory generating techniques have been developed (Garry and Wade 2005) which have led to false memories in up to $78 \%$ of adults (Lindsay et al. 2004) and 88\% of children (Otgaar, Candel, and Merckelbach 2008). In light of these studies and in light of what we know about memories of traumatic events, we can conclude that not only is recovery of repressed memories, at best, a rare phenomenon, but that it is relatively easy to implant false memories in normal humans. We shall now consider some missiological applications in light of the dangers of false accusations.

\section{False Memories in a Missionary Context}

In this final section we will first discuss the reasons that false accusations of child abuse are especially dangerous in a missionary context. We will also examine which individuals are most vulnerable to false memories, and, finally, we will look at the signs that a recovered memory is more likely to be false.

The Dangers of False Accusations in Missionary Contexts. "Acquitting the guilty and condemning the innocent--the LORD detests them both" (Prov. 17:15, NIV). One of God's primary attributes is righteousness or justice. He is never 
pleased when the guilty are acquitted or the innocent are condemned. When the innocent are falsely accused, even if no formal judgment is made against them, relationships may be broken and trust damaged. False accusations against full time Christian workers, especially those involved in cross cultural ministry, are particularly damaging (Tanner, Wherry, and Zvonkovic 2012, Tanner, Zvonkovic, and Adams 2012).

False accusations against missionaries may have more negative consequences for the accused than for members of other professions. Missionaries tend to already suffer from high stress levels due to multiple demands involving unrealistic expectations. In their home culture, not only are most missionaries expected to change the world (or at least one culture) for Christ, they are expected to raise their own funds to do so. In the culture in which they are serving, missionaries are subject to the intrusive demands that are often placed on clergy: personal criticism from multiple sources, unrealistic expectations that might not be expressed, ambiguity of boundaries involving personal and professional life, and criticism of family life (Lee 1999). These stressors by themselves are enough to lead to burn out; when false accusations are added to the mixture, the increased stress can be traumatic (Tanner, Wherry, and Zvonkovic 2012).

When false accusations are made, a missionary's social support system crumbles. Their churches both at home and abroad may abandon them. False accusations which lead to forced termination may be financially devastating. Missionaries have no unemployment insurance and because of their low salaries, may have little in savings. The stigma associated with being accused of childhood sexual abuse will most likely make it impossible to continue in their career. Marcus Tanner of Texas Tech University leads a research program on forced termination of clergy. In one study of clergy who experienced forced termination (Tanner, Wherry, and Zvonkovic 2012), $46 \%$ of the participants had symptoms that would allow for a PTSD diagnosis if forced termination were considered a traumatic event. This rate of PTSD is similar to that of victims of childhood sexual abuse $(12.2 \%$ for males and $26.5 \%$ for females; Kessler et al. 1995).

This means that mission organizations must do all they can to not only prevent childhood sexual abuse, but they must also do all they can to protect missionaries from false accusations of childhood sexual abuse. Both sexual abuse and false accusations may devastate the victims. Most mission organizations have taken steps to lower the risk of childhood sexual abuse; they must also be prepared to deal justly with accusations of abuse which might be false.

\section{Individuals More Likely to Experience False}

Memories. Although it is possible to create false memories in many people, there is no known technique for creating false memories in everyone. The question arises, "Under what conditions are people are more likely to develop false memories?"

People undergoing therapy with therapists who seek to recover repressed memories are the most likely candidates for false memories (Loftus and Davis 2006). In the last 20 years, many therapists have been sued for implanting false memories so the practices associated with memory recovery (hypnosis, suggestion, guided imagery, dream interpretation, etc.) are perhaps less common than they used to be. However, therapists and unlicensed counselors who were trained before the late 1990s and those trained outside of a research university (which is common in Christian circles) may still use techniques that frequently generate false memories.

In addition, research has found that people who think it is likely that they will one day begin psychotherapy tend to believe that the therapist will be able to uncover repressed childhood trauma, predisposing themselves to even inadvertent suggestions of abuse (Rubin and Boals 2010). Similarly, people who participate in online support groups for survivors will be exposed to suggestions that they were abused and are thus more susceptible to false memories (Loftus and Davis 2006). Susceptibility to false memories also increases after exposure to media coverage of people claiming to have recovered repressed memories (McNally and Geraerts 2009).

Children of missionaries (Missionary kids or MKs) may also be more susceptible to the implantation of false memories. Due to being raised in two or more cultures, MKs may have more psychosocial challenges as they move into adulthood than monocultural individuals (Wrobbel and Plueddemann 1990, Klemens and Bikos 2009). Some MKs may see being raised multi-culturally as the source of the challenges they face; others may seek other reasons for these challenges. People who desire an external cause for their internal struggles may be especially prone to developing false memories. Research has shown that one especially effective way to justify 
having problems without having to accept personal responsibility for them is to accuse others of wrong doing. Innuendo and accusations concerning others lead to higher evaluations of the accuser, both in the eyes of the accuser and of third parties (Rucker and Pratkanis 2001). By increasing the apparent guilt of a target, the culpability of the accuser is decreased. This is especially true when the reputation of the accuser is in question; such accusations reduce reservations that a third party might have concerning an accuser's character (Rucker and Petty 2003).

\section{When are "Recovered" Memories of Abuse More Likely to Be False? Because both child} abuse and false accusations may have devastating effects, mission organizations need to deal with accusations and discern what the underlying truth is. The therapeutic techniques that are most likely to implant false memories are still used by some counselors. In addition, some attorneys may seek to develop new markets by encouraging lawsuits against Protestant organizations now that the settlements against Catholic organizations are beginning to decline (Nussbaum and Sidebotham 2011).

The following list, adapted from McNally and Geraerts' list (2009, p. 132), describes when recovered memories of childhood sexual abuse are more likely to be false. The presence of any of these indicators does not prove that a recovered memory is false. They are statistically validated signs whose presence indicates a higher likelihood that the memories are false. In addition, it should be noted that false accusations may be made which are not based on false recovered memories; false accusations can be made for any number of possible reasons. The following signs simply reflect, based on empirical research, how false recovered memories tend to differ from true memories.

Memories are more likely to be false when:

1. The claimed abuse is perceived as traumatic when it occurred. Traumatic sexual abuse tends not to be forgotten. However, if the abuse was not perceived at the time as traumatic, it may be forgotten until reminders occur in the victim's environment.

2. The claimed abuse occurred multiple times. Multiple instances of abuse are more likely to be traumatic and not likely to be forgotten. Abuse that occurred once or just a few times is more likely to be forgotten.

3. The claimed abuse was understood to be sexual when it occurred. Abuse that is perceived to be sexual is more likely to be remembered than abuse that was not perceived to be sexual.

4. The offenders or places where the claimed abuse occurred continued to be present in the life of the abused. Places and people present at the place of abuse serve as reminders of the abuse. If the victim continues to have these in his or her life after the abuse, they serve as reminders and forgetting the abuse is less likely.

5. The recollections of abuse occur gradually as an adult. Verified recovered memories of abuse tend to occur suddenly when the victim encounters a reminder of the abuse. In contrast, false memories tend to develop slowly as individuals try to develop a narrative that explains their present condition.

6. The recollections as an adult occur in therapy, survivors groups, or media exposure to recovering repressed memories. Such exposure increases the likelihood of suggestions of childhood sexual abuse which can become false memories.

7. There is no corroborating evidence. The presence of corroborating evidence may be the best indicator that the claims of abuse are real.

Childhood sexual abuse is always tragic. False accusations of childhood sexual abuse are also tragic. Mission organizations must do what they can to prevent abuse from occurring as well as prevent false accusations from destroying lives. Empirical studies of false and real memories have given us tools to help distinguish between the two and to fulfill the biblical command, "Hate what is evil; cling to what is good." (Romans 12:9, NIV)1'.

\footnotetext{
${ }^{1}$ The author thanks Robert J. Priest of Trinity Evangelical Divinity School and several anonymous reviewers for helpful comments that have served to improve this paper in multiple ways.
} 


\section{References}

American Medical Association. 1994. Memories of childhood abuse. Report \#5-A-94 of the Council of Scientific Affairs. Washington, DC: American Medical Association.

American Psychiatric Association. 1994. Statement on memories of sexual abuse. Washington, DC: American Psychiatric Association.

Arnold Barr, R. 1994. My Lives. New York, NY: Ballantine.

Bass, E., and L. Davis. 1988. Courage to Heal: A Guide for Women Survivors of Child Sexual Abuse, No.: ISBN 0-06-055105-4. New York, NY: Perenniel Library.

Braun, K. A., R. Ellis, and E. F. Loftus. 2002. "Make my memory: How advertising can change our memories of the past." Psychology \& Marketing no. 19 (1):1-23.

Ceci, S. J., M. L. Crotteau Huffman, E. Smith, and E. F. Loftus. 1994. "Repeatedly Thinking about a Non-event: Source Misattributions among Preschoolers." Consciousness and Cognition no. 3 (3):388407.

Corwin, D. L., and E. Olafson. 1997. "Videotaped discovery of a reportedly unrecallable memory of child sexual abuse: Comparison with a childhood interview videotaped 11 years before." Child Maltreatment no. 2 (2):91-112.

de Rivera, Joseph. 1997. "The construction of false memory syndrome: The experience of retractors." Psychological Inquiry no. 8 (4):271-292.

Dinwiddie, Stephen, Andrew C Heath, Michael P Dunne, Kathleen K Bucholz, Pamela AF Madden, Wendy S Slutske, Laura J Bierut, Dixie B Statham, and Nicholas G Martin. 2000. "Early sexual abuse and lifetime psychopathology: A co-twin-control study." Psychological Medicine no. 30 (1):41-52.

Dunaetz, D. R. 2010. "Organizational Justice: Perceptions of Being Treated Fairly." In Serving Jesus with Integrity: Ethics and accountability in mission, edited by D. Baker and D. Hayward, 197-221. Pasadena, CA: William Carey Library.

Freud, S. 1962. "The aetiology of hysteria." In The Standard Edition of the Complete Psychological Works of Sigmund Freud, edited by A. Freud and J. Strachy, 187221. London, UK: Hogarth Press.
Garry, M., and K. A. Wade. 2005. "Actually, a picture is worth less than 45 words: Narratives produce more false memories than photographs do." Psychonomic Bulletin \& Review no. 12 (2):359-366.

Geraerts, E., J. W. Schooler, H. Merckelbach, M. Jelicic, B. J. A. Hauer, and Z. Ambadar. 2007. "The Reality of Recovered Memories: Corroborating Continuous and Discontinuous Memories of Childhood Sexual Abuse." Psychological Science no. 18 (7):564-568.

Goodman, Gail S, Simona Ghetti, Jodi A Quas, Robin S Edelstein, Kristen Weede Alexander, Allison D Redlich, Ingrid M Cordon, and David PH Jones. 2003. "A Prospective Study of Memory for Child Sexual Abuse New Findings Relevant to the RepressedMemory Controversy." Psychological Science no. 14 (2):113-118.

Goodman, Gail S, Jodi A Quas, and Christin M Ogle. 2010. "Child maltreatment and memory." Annual Review of Psychology no. 61:325351.

Health and Human Services. 2009. Child Maltreatment 2009. edited by Health and Human Services. Washington, DC: U.S. Department of Health and Human Services.

Holmes, E. A., R. J. Brown, W. Mansell, R. Fearon, E. Hunter, F. Frasquilho, and D. A. Oakley. 2005. "Are there two qualitatively distinct forms of dissociation? A review and some clinical implications." Clinical Psychology Review no. 25 (1):1-23.

Hyman, I. E., T. H. Husband, and F. J. Billings. 1995. "False memories of childhood experiences." Applied Cognitive Psychology no. 9 (3):181-197.

Kessler, R. C., A. Sonnega, E. Bromet, M. Hughes, and C. B. Nelson. 1995. "Posttraumatic stress disorder in the National Comorbidity Survey." Archives of General Psychiatry no. 52 (12):1048-1060.

Klemens, M. J., and L. H. Bikos. 2009. "Psychological well-being and sociocultural adaptation in college-aged, repatriated, missionary kids." Mental Health, Religion and Culture no. 12 (7):721-733.

Lacy, J. W., and C. E. L. Stark. 2013. "The neuroscience of memory: Implications for the courtroom." Nature Reviews Neuroscience no. 14 (9):649-658. 
Lee, C. 1999. "Specifying intrusive demands and their outcomes in congregational ministry: A report on the Ministry Demands Inventory." Journal for the Scientific Study of Religion no. 38:477-489.

Levitan, Robert D, Neil A Rector, Tess Sheldon, and Paula Goering. 2003. "Childhood adversities associated with major depression and/or anxiety disorders in a community sample of Ontario: Issues of co-morbidity and specificity." Depression and Anxiety no. 17 (1):34-42.

Lief, H. I., and J. Fetkewicz. 1995. "Retractors of false memories: The evolution of pseudomemories." Journal of Psychiatry and Law no. 23:411-435.

Lindsay, D. S., L. Hagen, J. D. Read, K. A. Wade, and M. Garry. 2004. "True photographs and false memories." Psychological Science no. 15 (3):149-154.

Loftus, E. F. 2003. "Make-believe memories." American Psychologist no. 58 (11):867-73.

Loftus, E. F., and D. Davis. 2006. "Recovered memories." Annual Review of Clinical Psychology no. 2:469-498.

Loftus, E. F., and M. J. Guyer. 2002. "Who abused Jane Doe? The hazards of the single case history. Part I." Skeptical Inquirer no. 26 (3):24-32.

Loftus, E. F., and K. Ketcham. 1994. The myth of repressed memory: False memories and allegations of sexual abuse. New York, NY: St. Martin's Press.

Loftus, E. F., and L. A. Rosenwald. 1993. "Buried memories, shattered lives." American Bar Association Journal no. 79 (11):70-73.

Maran, M. 2010. My lie: A true story offalse memory. San Francisco, CA: Jossey-Bass.

McNally, R. J. 2003. Remembering Trauma. Cambridge, MA: Harvard University Press.

McNally, R. J. 2012. "Explaining "Memories" of Space Alien Abduction and Past Lives: An Experimental Psychopathology Approach." Journal of Experimental Psychopathology no. 3:2-16.

McNally, R. J., and E. Geraerts. 2009. "A new solution to the recovered memory debate." Perspectives on Psychological Science no. 4 (2):126-134.

McNally, R. J., C. A. Perlman, C. S. Ristuccia, and S. A. Clancy. 2006. "Clinical characteristics of adults reporting repressed, recovered, or continuous memories of childhood sexual abuse." Journal of Consulting and Clinical Psychology no. 74 (2):237.
Nussbaum, L. M., and T. L. Sidebotham. 2011. Are Protestant Ministries a New Market? Lessons Learned from the Catholic Sexual Abuse Scandal. http://www.rothgerber.com/files/10436 AreProtestantMinistriesaN ewMarketv3. pdf.

Ost, James, Alan Costall, and Ray Bull. 2001. "False confessions and false memories: a model for understanding retractors' experiences." The Journal of Forensic Psychiatry no. 12 (3):549-579.

Otgaar, H., I. Candel, and H. Merckelbach. 2008. "Children's false memories: Easier to elicit for a negative than for a neutral event." Acta Psychologica no. 128 (2):350-354.

Patihis, L., L. Y. Ho, I. W. Tingen, S. O. Lilienfeld, and E. F. Loftus. in press. "Are the "Memory Wars" Over? A ScientistPractitioner Gap in Beliefs About Repressed Memory." Psychological Science.

Pendergrast, M. 1996. Victims of memory: Sex abuse accusations and shattered lives. Hinesberg, VT: Upper Access Books.

Perner, Josef, and Ted Ruffman. 1995. "Episodic Memory and Autonoetic Conciousness: Developmental Evidence and a Theory of Childhood Amnesia." Journal of Experimental Child Psychology no. 59 (3):516-548.

Pope, H. G., and J. I. Hudson. 1995. "Can individuals "repress" memories of childhood sexual abuse? An examination of the evidence." Psychiatric Annals no. 25:715-719.

Priest, R. J., and E. E. Cordill. 2012. "Christian Communities and "Recovered Memories" of Abuse." Christian Scholar's Review no. 41 (4):381-400.

Rediger, G. L. 1990. Ministry \& sexuality: Cases, counseling, care. Minneapolis, MN: Fortress Press.

Robbins, S. 2002. " Social and Cultural Forces Were Partially Responsible for Satanic Panic." In Satanism, edited by T. L. Roleff, 91-102. San Diego, CA: Greenhaven Press.

Rubin, David C, and Adriel Boals. 2010. "People who expect to enter psychotherapy are prone to believing that they have forgotten memories of childhood trauma and abuse." Memory no. 18 (5):556-562.

Rucker, D. D., and R. E. Petty. 2003. "Effects of accusations on the accuser: The moderating role of accuser culpability." 
Personality and Social Psychology Bulletin no. 29 (10):1259-1271.

Rucker, D. D., and A. R. Pratkanis. 2001.

"Projection as an interpersonal influence tactic: The effects of the pot calling the kettle black." Personality and Social Psychology Bulletin no. 27 (11):14941507.

Schacter, D. L. 1996. Searching for memory: The brain, the mind, and the past. New York, NY: Basic Books.

Schacter, D. L. 2001. The seven sins of memory. New York, NY: Houghton Mifflin.

Singer, M. T., and A. Nievod. 2003. "New age therapies." In Science and Pseudoscience in Clinical Psychology, edited by S. O. Lilienfeld, S. J. Lynn and J. M. Lohr, 176204. New York, NY: Guilford Press.

Tanner, M. N., J. N. Wherry, and A. M. Zvonkovic. 2012. "Clergy who experience trauma as a result of forced termination." Journal of Religion and Health:1-15. doi: doi:10.1007/s10943-012-9571-3.

Tanner, M. N., A. M. Zvonkovic, and C. Adams. 2012. "Forced termination of American clergy: Its effects and connection to negative well-being." Review of Religious Research no. 54 (1):1-17.

Terry, K. J., M. L. Smith, K. Schuth, J. R. Kelly, B. Vollman, and C. Massey. 2011. The Causes and Context of Sexual Abuse of Minors by Catholic Priests in the United States, 19502010: A Report Presented by the United States Conference of Catholic Bishops by the John Jay College Research Team. Washington, DC: United States Conference of Catholic Bishops.

Tracy, S. R. 2005. Mending the soul: Understanding and healing abuse. Grand Rapids, MI: Zondervan.

Widom, Cathy Spatz. 1999. "Posttraumatic stress disorder in abused and neglected children grown up." American Journal of Psychiatry no. 156 (8):1223-1229.

Williams, L. M. . 1994. "Recall of childhood trauma: A prospective study of women's memories of child sexual abuse." Journal of Consulting and Clinical Psychology no. 62:1167-1176.

Wrobbel, K. A., and J. E. Plueddemann. 1990. "Psychosocial development in adult missionary kids." Journal of Psychology and Theology no. 18:363-374.
Yehuda, Rachel. 2002. "Post-traumatic stress disorder." New England Journal of Medicine no. 346 (2):108-114.

Young, Mary. 1997. "The devil goes to day care: McMartin and the making of a moral panic." Journal of American Culture no. 20 (1):19-25. 